\title{
BMJ Open Period of residence in prefabricated temporary housing and psychological distress after the Great East Japan Earthquake: a longitudinal study
}

\author{
Fumiya Tanji, ${ }^{1}$ Yasutake Tomata, ${ }^{1}$ Takuya Sekiguchi, ${ }^{1,2}$ Ichiro Tsuji ${ }^{1}$
}

To cite: Tanji F, Tomata Y, Sekiguchi T, et al. Period of residence in prefabricated temporary housing and psychological distress after the Great East Japan Earthquake: a longitudinal study. BMJ Open 2018;8:e018211. doi:10.1136/ bmjopen-2017-018211

- Prepublication history and additional material for this paper are available online. To view please visit the journal (http:// dx.doi.org/10.1136/bmjopen2017-018211).

Received 13 June 2017 Revised 31 January 2018 Accepted 11 April 2018
Check for updates

${ }^{1}$ Division of Epidemiology, Department of Health Informatics and Public Health, Graduate School of Medicine, Tohoku University School of Public Health, Sendai, Japan ${ }^{2}$ Department of Orthopaedic Surgery, Tohoku University Graduate School of Medicine, Sendai, Japan

Correspondence to Mr Fumiya Tanji: ftanji-thk@umin.ac.jp

\section{ABSTRACT}

Objectives Previous studies have reported that displacement from one's own home after a natural disaster is associated with a higher degree of psychological distress. The present study investigated the longitudinal association between the period of residence in prefabricated temporary housing and psychological distress after the Great East Japan Earthquake. Design, setting and participants We conducted a longitudinal observation of 284 adults (aged $\geq 18$ years) who had lived in prefabricated temporary housing in Miyagi, Northeastern Japan. The period of residence in prefabricated temporary housing was classified into three categories: $<3,3-4$ and $>4$ years (ie, still living in prefabricated temporary housing).

Outcomes The Kessler 6-item Psychological Distress Scale (K6) was assessed in both a baseline survey (2011) and a follow-up survey (2016). Higher psychological distress was defined by a K6 score of $\geq 5$. We used Firth's penalised likelihood method in the multivariate logistic regression model to estimate the adjusted ORs and 95\% Cls.

Results Among the total participants, the proportion of individuals with higher psychological distress at the follow-up survey was significantly higher in the $>4$ years category (multivariate $\mathrm{OR}=4.00,95 \% \mathrm{Cl} 1.67$ to 10.16 ) than in the $<3$ years category. Among participants who had a lower degree of psychological distress at the baseline, the proportion of those whose psychological distress deteriorated was significantly higher in the $>4$ years category (multivariate $\mathrm{OR}=4.87,95 \% \mathrm{Cl} 1.26$ to 20.28 ) than in the $<3$ years category. On the other hand, among the participants who had a higher degree of psychological distress at the baseline, the proportion of those whose psychological distress ameliorated was significantly lower in the $>4$ years category (multivariate $0 \mathrm{R}=0.26,95 \% \mathrm{Cl}$ 0.06 to 0.85 ) than in the $<3$ years category.

Conclusions The proportion of individuals with more severe psychological distress was higher among participants who had lived in prefabricated temporary housing for a long period.

\section{INTRODUCTION}

The Great East Japan Earthquake (GEJE) and tsunami on 11 March 2011 not only took the lives of more than 15000 people but also

\section{Strengths and limitations of this study}

It is the first study to have examined the association between the period of residence in prefabricated temporary housing and psychological distress after a natural disaster.

- This longitudinal study differs from other studies of natural disaster survivors that had a cross-sectional design.

- Our sample size may have been rather small, making it difficult to classify participants into more than three categories of period of residence in prefabricated temporary housing.

- We were unable to obtain accurate information about the date of relocation for all subjects.

destroyed many private dwellings. ${ }^{1}$ Therefore, approximately 120000 victims were forced to live in prefabricated temporary housing. ${ }^{2-4}$ In accordance with the Japan Disaster Relief Act ${ }^{5}$ the designated period for living in prefabricated temporary housing is 2 years or less in principle. However, local governments may decide to extend the entering period if housing (eg, municipal housing) that has been provided for survivors is insufficient. ${ }^{6}$ This has meant that currently, 6 years after the GEJE, approximately 34000 victims are still living in prefabricated temporary housing. ${ }^{278}$ Therefore, a prolonged period of residence in prefabricated temporary housing is still a major problem after the GEJE.

Previous studies have reported that evacuation and displacement from one's own home after a natural disaster are associated with a higher degree of psychological distress. ${ }^{9-14}$ This problem is particularly acute for victims who have lived in prefabricated temporary housing. ${ }^{113}$ However, because these previous studies were cross-sectional in design, the impact of a prolonged period of residence in prefabricated temporary housing on psychological distress has remained unclear. 
The present study examined the longitudinal association between the period of residence in prefabricated temporary housing and psychological distress, after the GEJE.

\section{METHODS}

\section{Study design and participants}

The design of this study has been described in detail elsewhere. ${ }^{15}{ }^{16}$ In brief, we conducted baseline health surveys of residents aged 18 years or older who had lived in prefabricated temporary housing in Wakabayashi ward, Sendai City, Miyagi, Northeastern Japan, in September 2011. Health surveys involved an interview questionnaire and health check-up. We then followed up the residents with repeated self-administered questionnaires every 6 months to determine when they were able to leave this temporary housing, and we used the period of residence in such housing as the exposure variable. The study protocol was reviewed and approved by the Ethics Committee of Tohoku University Graduate School of Medicine.

Among the target population of 976 individuals who had lived in prefabricated temporary housing in the study area, $629(64.4 \%)$ participated in the baseline questionnaire survey in September 2011. We excluded 141 persons who did not consent to participate and 54 who did not enter any response to the questions for the Kessler 6-item Psychological Distress Scale (K6) ${ }^{17}$ Among the 434 remaining participants in September 2011, we excluded 17 who had died, 42 who were lost to follow-up and 76 who did not respond to the questionnaire survey in January 2016. Of the remaining 299 participants, we excluded 15 for whom K6 responses were missing in January 2016. Thus, a final total of 284 participants were included in our analysis.

\section{Measurements}

Period of residence in prefabricated temporary housing (exposure) We defined the period from the baseline (September 2011) to the time point before relocation from prefabricated temporary housing as the exposure variable (ie, the period of residence in this type of housing). In each of the 10 questionnaire surveys conducted every half-year, participants were asked about their type of residence. We assumed that the time point when participants 'relocated' from prefabricated temporary housing was determined by the time point when they chose another form of housing. The completion of Public Reconstructing Housing delayed, and it took 3 years or more to become possible to live there, although the designated period for living in prefabricated temporary housing was within 2 years, originally. Therefore, in this study, the period of residence in prefabricated temporary housing was divided into three categories: $<3$ years, $3-4$ years and $>4$ years (ie, still living in prefabricated temporary housing).

Among the 284 participants, 79 observations about the type of residence before relocation were missing. Therefore, we assumed that the individuals concerned had continued to live in prefabricated temporary housing, and used a last observation carried forward (LOCF) approach for imputing missing data for the type of residence.

\section{Psychological distress (outcome)}

The K6 was adopted as a measure of psychological distress. The Japanese version of the K6 has been validated previously. ${ }^{18}$ It consists of six questions about how often an individual has felt the following in the last month: (1) nervous, (2) hopeless, (3) restless or fidgety, (4) so sad that nothing could cheer you up, (5) everything was an effort and (6) worthless. The total K6 score ranged from 0 to 24 .

Similarly to previous studies, we classified respondents with K6 scores of $\geq 5$ as having psychological distress. ${ }^{14}$ 19-22

However, as some studies have classified K6 scores of $\geq 13$ as representing a higher degree of psychological distress, ${ }^{14} 23-25$ we also conducted a sensitivity analysis using this cut-off point.

\section{Covariates}

The questionnaire requested the following information from each participant: age, sex, self-rated health, subjective economic status and social ties.

Self-rated health was assessed by the question 'How do you rate your state of health?', for which available responses were 'Very good', 'Somewhat good', 'Not good' and 'Bad'. Subjective economic status was assessed by the question 'How do you feel about the current state of your household economy?', for which available responses were 'Poorest', 'Poorer', 'Poor' and 'Fair'. Social ties were assessed by the following four questions: 'Do the people around you help each other?', 'Can you trust the people around you?', 'Do the people around you greet one another?' and 'If some sort of problem occurs, do the people around you work together to try and solve it?'. The participants were asked to choose one of the following responses: 'Not at all', 'Not really', 'Neither', 'True to some extent' and 'Very true'. The answers were scored from 0 to 4 points on a scale of increasing positivity, and the total score for all four questions (0-16 points) was calculated. We classified respondents with social ties scores of $\geq 9$ as having strong ties. ${ }^{26}$

\section{Statistical analysis}

Baseline characteristics (in September 2011) were evaluated by using the $\chi^{2}$ test for categorical variables and analysis of variance for continuous variables. We conducted longitudinal analyses to evaluate the association between the period of residence in prefabricated temporary housing and psychological distress at the time of the follow-up survey (in January 2016). Additionally, to evaluate whether the degree of subsequent change in psychological distress had changed as a result of the above exposure, we conducted subgroup analyses by stratifying the participants by their degree of psychological distress at the baseline (lower psychological distress; higher psychological distress). The 
dependent variable was the change in the degree of psychological distress, that is, deterioration (a change from lower to higher psychological distress) or amelioration (a change from higher to lower psychological distress). We then used Firth's penalised likelihood method in the multivariate logistic regression model to calculate the adjusted ORs and 95\% CIs because there was a need to consider sparse data bias. ${ }^{27}$ Additionally, among 434 participants who completed the $\mathrm{K} 6$ at the baseline survey, we conducted analyses using the Linear mixed model in order to consider time (study phase) and outcome as continuous variables. For cases where values for a confounding variable were missing, we created a separate missing category and included this in the model. Respondents whose period of residence was $<3$ years (the lowest category) were defined as a reference category. To test for linear trends, we entered the categories of the period of residence in prefabricated temporary housing as ordinal numbers $(<3$ years, 3-4 years or $>4$ years: 1,2 or 3 ) in the corresponding logistic regression model.

We considered the following variables to be potential confounders (adjustment items): age (continuous variable), sex (man or woman), K6 score at the baseline (continuous variable), self-rated health (good (very good or somewhat good), bad (not good or bad) or missing), subjective economic status (poorest, fair to poorer or missing) and social ties (strong ties, weak ties or missing) at the baseline.

All statistical analyses were performed using the SAS software package V.9.4 (SAS Institute). All statistical tests were two-sided, and differences at $\mathrm{p}<0.05$ were accepted as significant.

\section{RESULTS}

Baseline characteristics according to period of residence in prefabricated temporary housing

Baseline characteristics according to each period of residence in prefabricated temporary housing are shown in table 1. Participants who lived in this type of housing for $>4$ years (ie, still living in prefabricated temporary housing) were younger $(\mathrm{p}=0.031)$. However, with respect to other variables, there was no significant difference among the three categories. There was no significant difference of the proportion of individuals with $\mathrm{K} 6$ scores of $\geq 5$ according to the period of residence in prefabricated temporary housing at the baseline $(\mathrm{p}=0.872)$.

Table 1 Baseline characteristics of participants according to period of residence in prefabricated temporary housing ( $\mathrm{n}=284)$

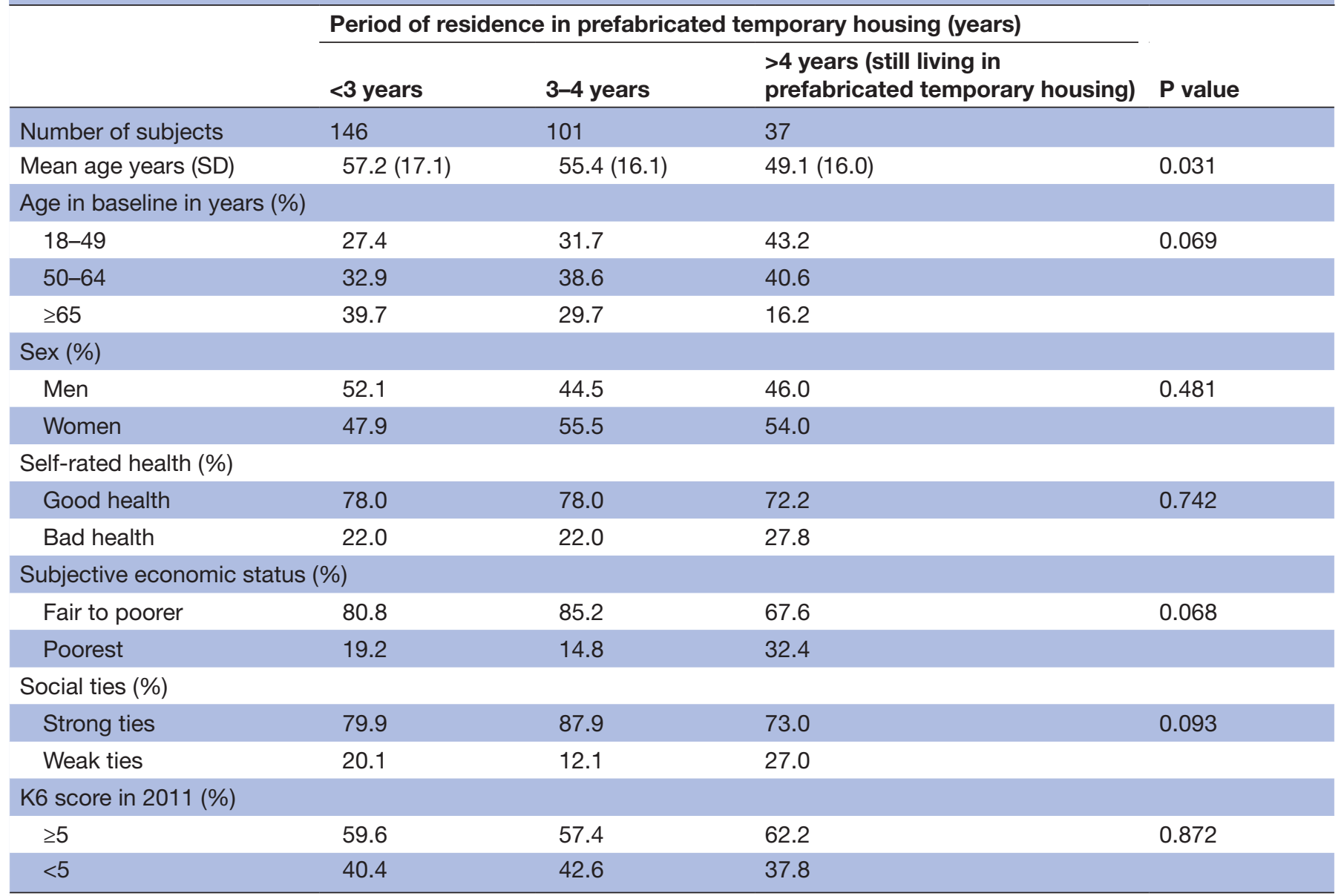

K6, Kessler 6-Item Psychological Distress Scale. 
Table 2 Association between period of residence in prefabricated temporary housing and psychological distress during 4.3 years after the Great East Japan Earthquake $(n=284)$

\begin{tabular}{|c|c|c|c|c|}
\hline & \multicolumn{3}{|c|}{ Period of residence in prefabricated temporary housing (years) } & \multirow[b]{2}{*}{ P trend } \\
\hline & $<3$ years & $3-4$ years & $\begin{array}{l}>4 \text { years (still living in } \\
\text { prefabricated temporary } \\
\text { housing) }\end{array}$ & \\
\hline Number of subjects & 146 & 101 & 37 & \\
\hline $\begin{array}{l}\text { Number of subjects with higher } \\
\text { psychological distress }\end{array}$ & 61 & 45 & 27 & \\
\hline Crude OR $(95 \% \mathrm{Cl})$ & 1.00 (reference) & $1.12(0.67$ to 1.87$)$ & 3.64 (1.71 to 8.28$)$ & 0.005 \\
\hline Age-sex adjusted OR (95\% Cl) & 1.00 (reference) & $1.12(0.66$ to 1.88$)$ & $4.22(1.92$ to 9.87$)$ & 0.003 \\
\hline Multivariate adjusted OR $(95 \% \mathrm{Cl}) \dagger$ & 1.00 (reference) & 1.12 (0.63 to 2.01$)$ & $4.00(1.67$ to 10.16$)$ & 0.010 \\
\hline
\end{tabular}

${ }^{*}$ Higher psychological distress was defined as K6 score $\geq 5$ at the follow-up survey (2016).

†Adjustment items were age, sex, K6 score at baseline, subjective economic status (poorest, fair to poorer or missing), social ties (strong ties, weak ties or missing) and self-rated health (good health, bad health or missing).

K6, Kessler 6-Item Psychological Distress Scale.

\section{Association between the period of residence in prefabricated temporary housing and psychological distress during 4.3 years after the GEJE}

Among total participants $(\mathrm{n}=284)$, the number who showed more severe psychological distress was 133 at the time of the follow-up survey. Table 2 shows the association between the period of residence in prefabricated temporary housing and psychological distress at the time of the follow-up survey. In comparison with the $<3$ years group, the multivariate adjusted OR for higher psychological distress in the $>4$ years group showed a significant increase (multivariate $\mathrm{OR}=4.00,95 \%$ CI 1.67 to 10.16 , $\mathrm{p}$-trend $=0.010$ ). Among 434 participants who completed the $\mathrm{K} 6$ at the baseline survey, we tested whether the period of residence in prefabricated temporary housing was associated with changes in psychological distress from 2011 to 2016 using the linear mixed model (online supplementary table S1). This revealed that the mean K6 score was higher in the $>4$ years group than in the $<3$ years group (p-interaction $=0.011)$.

\section{Changes in psychological distress}

We stratified the participants according to their degree of psychological distress at the baseline. Between 2011 and $2016,30.3 \%$ of participants retained a lower levels of distress, $10.6 \%$ showed deterioration, $22.9 \%$ ameliorated and $36.2 \%$ retained a higher levels of distress (table 3 ).

\section{Longitudinal analysis: deterioration of psychological distress among participants with lower psychological distress at the baseline}

Among 116 subjects who had shown a lower degree of psychological distress at the baseline, number of participants who showed deterioration of psychological distress was 30 at the time of the follow-up survey. Table 4 shows the association between the period of residence in prefabricated temporary housing and deterioration of psychological distress among participants who had shown lower psychological distress (K6 score $<5)$ at the baseline. In comparison with the $<3$ years group, the multivariate adjusted OR for deterioration of psychological distress in the $>4$ years group showed a significant increase (multivariate $\mathrm{OR}=4.87,95 \%$ CI 1.26 to 20.28 , $\mathrm{p}$-trend $=0.032$ ).

Longitudinal analysis: amelioration of psychological distress among participants with higher psychological distress at the baseline

Among 168 subjects who had shown a higher degree of psychological distress at the baseline, the number of participants who showed amelioration of psychological distress was 65 at the time of the follow-up survey. Table 5 shows the association between the period of residence in prefabricated temporary housing and amelioration of psychological distress among participants who had shown higher psychological distress (K6 score $\geq 5$ ) at the baseline. In comparison with the $<3$ years group, the multivariate adjusted OR for amelioration of psychological distress in the $>4$ years group showed a significant decrease (multivariate $\mathrm{OR}=0.26,95 \%$ CI 0.06 to 0.85 ) although there was a marginally significant dose-response relationship (p-trend $=0.082$ ).

Table 3 Category of change in psychological distress 2016

\begin{tabular}{ll}
\hline $\begin{array}{l}\text { Lower } \\
\text { psychological } \\
\text { distress } \\
\text { (K6 score <5) }\end{array}$ & $\begin{array}{l}\text { Higher } \\
\text { psychological } \\
\text { distress } \\
\text { (K6 score } \geq 5)\end{array}$ \\
$\begin{array}{l}\text { Remained lower } \\
\text { distress } \\
n=86(30.3 \%)\end{array}$ & $\begin{array}{l}\text { Deterioration } \\
\mathrm{n}=30(10.6 \%)\end{array}$ \\
$\begin{array}{l}\text { Amelioration } \\
\mathrm{n}=65(22.9 \%)\end{array}$ & $\begin{array}{l}\text { Remained higher } \\
\text { distress } \\
\mathrm{n}=103(36.2 \%)\end{array}$ \\
&
\end{tabular}

K6, Kessler 6-Item Psychological Distress Scale. 
Table 4 Association between period of residence in prefabricated temporary housing and deterioration of psychological distress among the subjects with lower psychological distress (K6 score $<5)$ at the baseline $(n=116)$

\begin{tabular}{|c|c|c|c|c|}
\hline & \multicolumn{3}{|c|}{ Period of residence in prefabricated temporary housing (years) } & \multirow[b]{2}{*}{$\mathbf{P}$ trend } \\
\hline & $<3$ years & 3-4 years & $\begin{array}{l}>4 \text { years (still living in } \\
\text { prefabricated temporary } \\
\text { housing) }\end{array}$ & \\
\hline Number of subjects & 59 & 43 & 14 & \\
\hline Number of subjects with deterioration* & 12 & 11 & 7 & \\
\hline Crude OR $(95 \% \mathrm{Cl})$ & 1.00 (reference) & 1.35 (0.53 to 3.38$)$ & $3.80(1.15$ to 12.78$)$ & 0.049 \\
\hline Multivariate adjusted OR (95\% Cl)† & 1.00 (reference) & $1.76(0.61$ to 5.29$)$ & 4.87 (1.26 to 20.28$)$ & 0.032 \\
\hline
\end{tabular}

${ }^{*}$ Deterioration was defined as the change from lower (K6 score <5) (2011) to higher psychological distress (K6 score $\left.\geq 5\right)(2016)$.

†Adjustment items were age, sex, K6 score at baseline, subjective economic status (poorest, fair to poorer or missing), social ties (strong ties, weak ties or missing) and self-rated health (good health, bad health or missing).

\section{Sensitivity analysis}

For the results shown in table 2, we conducted a stratified analysis by sex, but the findings remained unchanged (online supplementary table S2).

In addition, we conducted sensitivity analyses using a K6 score of $\geq 13$ as the cut-off, but the results remained unchanged (online supplementary table S3).

\section{DISCUSSION}

In this study, we examined the longitudinal association between the period of residence in prefabricated temporary housing and psychological distress after the GEJE. The proportion of higher psychological distress (K6 score $\geq 5$ ) was significantly higher among participants who had lived in prefabricated temporary housing for $>4$ years than those who had lived there for $<3$ years at the time of the follow-up survey. Among participants who had shown lower psychological distress (K6 score $<5)$ at the baseline, the proportion of those who showed deterioration of psychological distress was significantly higher when they had lived in prefabricated temporary housing for $>4$ years than when they had lived there for $<3$ years.
Among participants who had shown higher psychological distress (K6 score $\geq 5)$ at the baseline, the proportion of those whose psychological distress ameliorated was significantly lower when they had lived in prefabricated temporary housing for $>4$ years than when they had lived there for $<3$ years.

In the present study, we classified respondents with K6 scores of $\geq 5$ as having a higher degree of psychological distress. However, as several previous studies have used a K6 score of $\geq 13$ as the cut-off point for severe psychological distress, ${ }^{14}{ }^{23-25}$ we performed sensitivity analyses after changing the cut-off point. However, the result was consistent with our main findings.

A cross-sectional study has reported that complaints about the residential conditions was associated with psychological distress among GEJE survivors living in temporary housing. ${ }^{11}$ Also, a cross-sectional study has reported that favourable housing conditions were associated with psychological well-being. ${ }^{28}$ The prefabricated temporary housing provided for disaster survivors is considerably smaller than the former private residences they lived. This means that noise from neighbours,

Table 5 Association between period of residence in prefabricated temporary housing and amelioration of psychological distress among the subjects with higher psychological distress (K6 score $\geq 5)$ at the baseline $(n=168)$

Period of residence in prefabricated temporary housing (years)

\begin{tabular}{|c|c|c|c|c|}
\hline & \multicolumn{3}{|c|}{ Period of residence in prefabricated temporary housing (years) } & \multirow[b]{2}{*}{ P trend } \\
\hline & $<3$ years & 3-4 years & $\begin{array}{l}>4 \text { years (still living in } \\
\text { prefabricated temporary } \\
\text { housing) }\end{array}$ & \\
\hline Number of subjects & 87 & 58 & 23 & \\
\hline Number of subjects with amelioration* & 38 & 24 & 3 & \\
\hline Crude OR (95\% Cl) & 1.00 (reference) & 0.89 (0.45 to 1.72$)$ & 0.23 (0.06 to 0.70$)$ & 0.033 \\
\hline Age-sex adjusted OR (95\% Cl) & 1.00 (reference) & 0.87 (0.44 to 1.70$)$ & 0.21 (0.05 to 0.66$)$ & 0.028 \\
\hline Multivariate adjusted OR $(95 \% \mathrm{Cl}) \dagger$ & 1.00 (reference) & $0.93(0.46$ to 1.88$)$ & $0.26(0.06$ to 0.85$)$ & 0.082 \\
\hline
\end{tabular}

*Amelioration was defined as the change from higher (K6 score $\geq 5)(2011)$ to lower psychological distress $(K 6$ score <5) $(2016)$.

†Adjustment items were age, sex, K6 score at baseline, subjective economic status (poorest, fair to poorer or missing), social ties (strong ties, weak ties or missing) and self-rated health (good health, bad health or missing).

K6, Kessler 6-Item Psychological Distress Scale. 
including conversations and other sounds of daily life, is heard more easily and is intrusive. Therefore, prolonged residence in prefabricated temporary housing might lead to deterioration of psychological distress and impair amelioration of psychological distress.

Another study has reported that individuals who are unable to make future housing plans are at a higher risk of psychological distress. ${ }^{19}$ Survivors were forced to live in prefabricated temporary housing for long periods because, for a variety of reasons, it was not possible for them to make future housing plans. Our results showed that individuals who had been living in prefabricated temporary housing for a long time were more likely to feel that their household economy was 'poorest'. It has been reported that people who had social handicaps such as unemployment, decreased income, work instability and undetermined resettlement continuously demanded psychosocial support in the mid-term to long-term phase after the GEJE. ${ }^{29}$ Therefore, difficulties in reconstructing their own lives as a result of prolonged residence in such temporary housing might have an impact on psychological distress.

Our present study had several strengths. First, it is the first study to have examined the association between the period of residence in prefabricated temporary housing and psychological distress after a natural disaster. Second, this longitudinal study represents our continuous efforts to prospectively undertake questionnaire surveys in the aftermath of the GEJE. This approach differs from other studies of natural disaster survivors that had a cross-sectional design.

On the other hand, our study also had some limitations. First, our sample size may have been rather small, making it difficult to classify participants into more than three categories of period of residence in prefabricated temporary housing. Second, we were unable to obtain accurate information about the date of relocation for all subjects. Because we replaced missing data using the last observed data for that variable (LOCF approach), we might have overestimated the period of residence in prefabricated temporary housing. This misclassification might have led to underestimation of the association between the period of residence and psychological distress. ${ }^{30} 31$ Third, among the source population of 976 , the population of $284(29.0 \%)$ analysed in our study was small. The present study might have been biased towards the healthier people. However, the proportions of individuals with $\mathrm{K} 6 \geq 5$ among the analysed and excluded subjects (264 people who entered responses to the K6 items) were similar: $59.2 \%$ vs $60.2 \%$. Fourth, we did not consider typical controlled variables, such as predisaster factors and exposure to disaster stressors.

\section{CONCLUSION}

Long-term residence in prefabricated temporary housing was associated with higher psychological distress for 4.3 years after the GEJE. These findings suggest that earlier reconstruction of homes might have a considerably beneficial effect on the psychological health of natural disaster survivors.

Acknowledgements The authors would like to thank Takashi Watanabe, Yoshiko Nakata, Mami Takahashi, Mao Suzuki and Fukuko Kano for their technical assistance.

Contributors All the authors have made a substantial contribution to the manuscript and have approved this submission. FT performed the data analyses and wrote the manuscript. YT and IT supervised the data analyses and the manuscript. TS helped to supervise the manuscript.

Funding This work was supported by Health Sciences Research Grants (H24, 25-Kenki-Shintei-002 (Fukkou)) from the Ministry of Health, Labour and Welfare of Japan.

Competing interests None declared.

Patient consent Obtained.

Ethics approval The study protocol was reviewed and approved by the Ethics Committee of Tohoku University Graduate School of Medicine.

Provenance and peer review Not commissioned; externally peer reviewed.

Data sharing statement № additional data available.

Open Access This is an Open Access article distributed in accordance with the Creative Commons Attribution Non Commercial (CC BY-NC 4.0) license, which permits others to distribute, remix, adapt, build upon this work non-commercially, and license their derivative works on different terms, provided the original work is properly cited and the use is non-commercial. See: http://creativecommons.org/ licenses/by-nc/4.0/

(c) Article author(s) (or their employer(s) unless otherwise stated in the text of the article) 2018. All rights reserved. No commercial use is permitted unless otherwise expressly granted.

\section{REFERENCES}

1. National Police Agency. Damage situation and police countermeasures (10 March 2017) (in Japanese). https://www.npa. go.jp/news/other/earthquake2011/pdf/higaijokyo.pdf (accessed 7 Jun 2017).

2. Fukushima Prefectural Government. Trend in the number of residents who lived in temporary housing (31 May 2017) (in Japanese). https:// www.pref.fukushima.lg.jp/uploaded/life/279148_666298_misc.pdf (accessed 7 Jun 2017).

3. Iwate Prefectural Government. The number of residents who lived in temporary housing (30 March 2011) (in Japanese). http://www.pref. iwate.jp/dbps_data/_material_/_files/000/000/023/870/23suii.pdf (accessed 7 Jun 2017).

4. Miyagi Prefectural Government. The number of residents who lived in temporary housing (March 2012) (in Japanese). https://www.pref. miyagi.jp/uploaded/attachment/204097.pdf (accessed 7 Jun 2017).

5. Cabinet Office of Japan. Disaster Relief Act (1 October 2013) (in Japanese). http://www.bousai.go.jp/taisaku/kyuujo/pdf/siryo7.pdf (accessed 12 Apr 2017).

6. Sendai City, reconstruction of Sendai (April 2016). http://www. city.sendai.jp/shinsaifukko/shise/daishinsai/fukko/documents/ thereconstructionofsendai_englishedition.pdf (accessed 7 Jun 2017).

7. Iwate Prefectural Government. The number of residents who lived in temporary housin (31 March 2017) (in Japanese). http:// www.pref.iwate.jp/dbps_data/_material_/_files/000/000/023/870/ 28nenndosuii2903.pdf (accessed 7 Jun 2017).

8. Miyagi Prefectural Government. The number of residents who lived in temporary housing (March 2017) (in Japanese). https://www.pref. miyagi.jp/uploaded/attachment/620937.pdf (accessed 7 Jun 2017).

9. Cao X, Jiang X, Pang S, et al. The prevalence and risk factors for psychological distress in older men and women affected by the Wenchuan, China earthquake. Australas J Ageing 2014;33:E20-6.

10. Fussell E, Lowe SR. The impact of housing displacement on the mental health of low-income parents after Hurricane Katrina. Soc Sci Med 2014;113:137-44.

11. Horikoshi N, Iwasa $\mathrm{H}$, Kawakami $\mathrm{N}$, et al. Residence-related factors and psychological distress among evacuees after the Fukushima Daiichi nuclear power plant accident: a cross-sectional study. BMC Psychiatry 2016;16:420. 
12. Kiliç C, Aydin I, Tașkintuna N, et al. Predictors of psychological distress in survivors of the 1999 earthquakes in Turkey: effects of relocation after the disaster. Acta Psychiatr Scand 2006;114:194-202

13. Kuwabara $\mathrm{H}$, Shioiri $\mathrm{T}$, Toyabe $\mathrm{S}$, et al. Factors impacting on psychological distress and recovery after the 2004 Niigata-Chuetsu earthquake, Japan: community-based study. Psychiatry Clin Neurosci 2008;62:503-7.

14. Yokoyama Y, Otsuka K, Kawakami N, et al. Mental health and related factors after the Great East Japan earthquake and tsunami. PLoS One 2014;9:e102497.

15. Hagiwara $Y$, Yabe $Y$, Sugawara $Y$, et al. Influence of living environments and working status on low back pain for survivors of the Great East Japan Earthquake. J Orthop Sci 2016;21:138-42.

16. Sone T, Nakaya N, Sugawara Y, et al. Longitudinal association between time-varying social isolation and psychological distress after the Great East Japan Earthquake. Soc Sci Med 2016;152:96-101.

17. Kessler RC, Andrews G, Colpe LJ, et al. Short screening scales to monitor population prevalences and trends in non-specific psychological distress. Psychol Med 2002;32:959-76.

18. Furukawa TA, Kawakami N, Saitoh M, et al. The performance of the Japanese version of the K6 and K10 in the World Mental Health Survey Japan. Int J Methods Psychiatr Res 2008;17:152-8.

19. Nakaya N, Nakamura T, Tsuchiya N, et al. Prospect of future housing and risk of psychological distress at 1 year after an earthquake disaster. Psychiatry Clin Neurosci 2016;70:182-9.

20. Sakurai K, Nishi A, Kondo K, et al. Screening performance of K6/K10 and other screening instruments for mood and anxiety disorders in Japan. Psychiatry Clin Neurosci 2011;65:434-41.

21. Schmitz N, Lesage A, Wang J. Should psychological distress screening in the community account for self-perceived health status? Can J Psychiatry 2009;54:526-33.
22. Prochaska JJ, Sung HY, Max W, et al. Validity study of the K6 scale as a measure of moderate mental distress based on mental health treatment need and utilization. Int J Methods Psychiatr Res 2012;21:88-97.

23. Fushimi M, Saito S, Shimizu T, et al. Prevalence of psychological distress, as measured by the Kessler 6 (K6), and related factors in Japanese employees. Community Ment Health J 2012;48:328-35.

24. Watanabe Z, Iwama N, Nishigori H, et al. Psychological distress during pregnancy in Miyagi after the Great East Japan Earthquake: The Japan Environment and Children's Study. J Affect Disord 2016;190:341-8.

25. Tanji F, Sugawara $Y$, Tomata $Y$, et al. Psychological distress and the incident risk of functional disability in elderly survivors after the Great East Japan Earthquake. J Affect Disord 2017;221:145-50.

26. Ito K, Tomata $\mathrm{Y}$, Kogure $\mathrm{M}$, et al. Housing type after the Great East Japan Earthquake and loss of motor function in elderly victims: a prospective observational study. BMJ Open 2016;6:e012760.

27. Greenland S, Mansournia MA, Altman DG. Sparse data bias: a problem hiding in plain sight. BMJ 2016;352:i1981.

28. Evans GW, Kantrowitz E, Eshelman P. Housing quality and psychological well-being among the elderly population. J Gerontol B Psychol Sci Soc Sci 2002;57:P381-P383.

29. Orui M, Harada S, Hayashi M, et al. Practical report on long-term disaster mental health services following the great east japan earthquake: psychological and social background of evacuees in sendai city in the mid- to long-term post-disaster period. Disaster Med Public Health Prep 2017;11:439-50.

30. Grimes DA, Schulz KF. Bias and causal associations in observational research. Lancet 2002;359:248-52.

31. Kim MY, Goldberg JD. The effects of outcome misclassification and measurement error on the design and analysis of therapeutic equivalence trials. Stat Med 2001;20:2065-78. 